\title{
A MP 495/10 E O ESTADO CONSUMIDOR COMO INDUTOR DE POLÍTICAS ECONÔMICAS
}

\section{INTERIM MEASURE 495/10 AND THE STATE-CONSUMER AS AN INDUCTOR OF ECONOMIC POLICES}

Polyane Denobi ${ }^{1}$

\begin{abstract}
RESUMO: O presente estudo tem por finalidade abordar a modalidade de intervenção indireta do Estado no domínio econômico, atuando como agente normativo e indutor da economia. Trata em especial sobre a utilização de sua condição de Estado-consumidor para influenciar o mercado devido ao seu significativo poder de compra. Baseado no exemplo das inovações trazidas pela Medida Provisória ${ }^{\circ}$ 495/2010 sobre a lei de licitações $n^{\circ} 8.666 / 93$, o estudo pretende demonstrar como o instituto das compras públicas tem se prestado como instrumento do Estado na criação de políticas públicas no campo econômico.
\end{abstract}

Palavras Chave: Estado consumidor; Contratações públicas; Desenvolvimento nacional; Políticas públicas; Intervenção indireta na ordem econômica.

\begin{abstract}
The objective of the present study is to approach the modality of indirect intervention of the State in the economic domain, acting as a normative agent and economy inductive. It deals especially with the condition of the State being a consumer itself in order to influence the market, due to its elevated purchasing power. Based on the models of innovations brought about by the Interim Measure \#495/2010, about the bidding laws \# 8.666/93, this study aims to demonstrate how the public purchasing institute has been lending itself as a tool for the State in the creation of public policies in the economic field.
\end{abstract}

Keywords: State-Consumer; Public procurement; National development; Public policies; Indirect intervention in the economic order.

\section{INTRODUÇÃO}

Verifica-se que o Estado vem se valendo de sua condição de consumidor para, por meio de atos normativos, estabelecer critérios de preferência em compras públicas, atuando como agente indutor do mercado.

Não há consenso na doutrina sobre a validade deste papel desempenhado pelo Estado, uma vez que a finalidade do instituto das licitações públicas, em tese, seria o de apenas promover a escolha pela Administração da proposta mais vantajosa à satisfação de suas necessidades imediatas, com a observância do princípio da isonomia.

No entanto o Estado tem se valido de seu poder de compra para criar estímulos aos seus fornecedores, protegendo determinados mercados, seja no âmbito interno como no inter-

\footnotetext{
${ }^{1}$ Especialista em Direito do Estado pela Universidade Estadual de Londrina. E-mail: po.denobi@hotmail.com.
} 
nacional, como aponta a recente Medida Provisória 495/2010, exemplo a ser tratado no presente estudo.(BRASIL, 2010).

Discute-se, ainda, a validade da utilização de medidas provisórias pelo Estado normativo, imiscuindo-se na ordem econômica sem a prévia aprovação do Poder Legislativo da política econômica proposta.

A discussão é importante, e tem por finalidade repensar a finalidade do instituto das licitações e contratações públicas, e a legitimidade de utilização do poder de compra do Estado para criar políticas públicas e estimular setores da economia.

\section{ALTERAÇÕES PROMOVIDAS PELA MP 495/2010 NO DOMÍNIO ECONÔMICO}

Recentemente o Poder Executivo Federal promulgou a Medida Provisória $n^{\circ} 495$, de 19 de julho de 2010, que alterou a Lei $n^{\circ}$. 8.666, de 21 de junho de 1993, lei esta que regulamenta $\mathrm{o}$ art. 37, inciso XXI, da Constituição Federal e institui normas para licitações e contratos da Administração Pública. (BRASIL, 1993).

Por meio desta normativa, fora modificado o artigo $3^{\circ}$ da lei 8.666/93, acrescentando a promoção do desenvolvimento nacional às demais finalidades da licitação, quais sejam, a de garantir a isonomia entre os licitantes e selecionar a proposta mais vantajosa para a Administração, in verbis:

Art. $3^{\circ}$ A licitação destina-se a garantir a observância do princípio constitucional da isonomia, a seleção da proposta mais vantajosa para a administração e a promoção do desenvolvimento nacional, e será processada e julgada em estrita conformidade com os princípios básicos da legalidade, da impessoalidade, da moralidade, da igualdade, da publicidade, da probidade administrativa, da vinculação ao instrumento convocatório, do julgamento objetivo e dos que lhes são correlatos. (Destacou-se) (BRASIL, 2010).

A medida não inova o ordenamento jurídico, uma vez que "garantir o desenvolvimento nacional" constitui objetivo fundamental da República Federativa do Brasil, conforme disposto no artigo $3^{\circ}$, inciso II da Constituição Federal de 1988. No entanto, a medida tem como finalidade justificar as demais alterações promovidas pela Medida Provisória, instrumento pelo qual o Estado-consumidor acaba por intervir no domínio econômico criando favorecimentos nas contratações públicas e, por conseqüência, estimular determinados setores da economia. 
Com vistas a materializar esta nova finalidade da licitação, buscou a MP 495 promover o desenvolvimento nacional estabelecendo um novo direito de preferência como critério de desempate para propostas em certames licitatórios que se encontrem em igualdade de condições. A Lei ${ }^{\circ} 8.666 / 93$ passou a vigorar com as seguintes alterações:

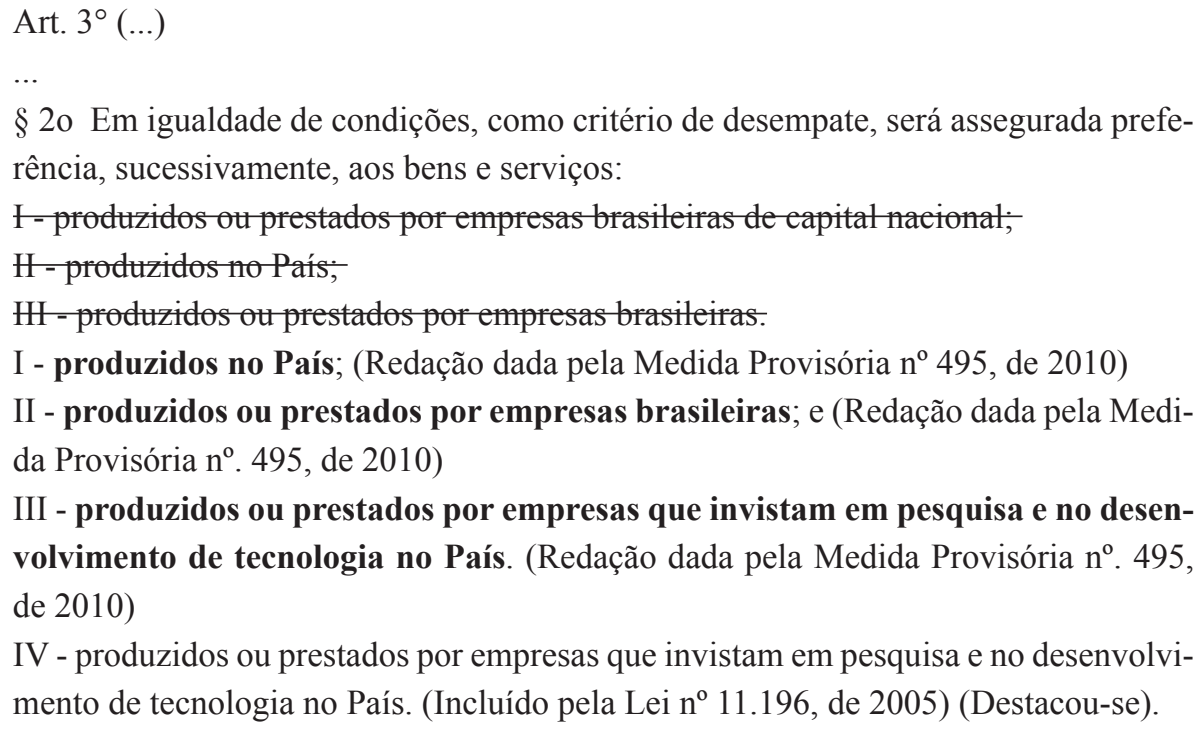

A medida teve como nítido intuito a proteção do mercado nacional, bem como o incentivo ao investimento em pesquisa e no desenvolvimento tecnológico do país. Além dessa medida que desiguala a competitividade entre empresas nacionais e estrangeiras, ainda dentro do mencionado intuito de promover o desenvolvimento nacional, criou-se margem de preferência à contratação de produtos manufaturados e serviços nacionais que atendam a normas técnicas brasileiras (Art. $3^{\circ}, \S^{\circ}$ lei 8.666/93). (BRASIL, 1993).

Sobre o que devam ser considerados produto manufaturados e serviços nacionais, a MP 495 cuidou de alterar o artigo $6^{\circ}$ da lei 8.666/93, acrescentando os incisos XVII e XVIII, considerando produtos manufaturados nacionais, aqueles produzidos no território nacional de acordo com o processo produtivo básico ou regras de origem estabelecidas pelo Poder Executivo Federal; bem como serviços nacionais aqueles prestados no País, nas condições estabelecidas pelo Poder Executivo Federal.

Conforme bem aponta Torres (2010, p. 5):

Os conceitos demonstram uma excessiva delegação ao Poder Executivo, para regulamentação da matéria, autorizando a quebra da isonomia através de ato infralegal. A disposição pode gerar abusos, por parte do poder regulamentar, dando ensejo a discussões jurídicas e judiciais profundas, acerca das margens de preferência estabelecidas 
por atos infralegal, que, inequivocamente, quebrarão o tratamento isonômico exigido pelo constituinte.

Como parâmetro objetivo para a aplicação do critério de preferência, o $\S^{\circ}$ do $\operatorname{artigo~} 3^{\circ}$ estabeleceu que a margem de preferência por produto, serviço, grupo de produtos ou grupo de serviços, a que refere o $\S 5^{\circ}$, será definida pelo Poder Executivo Federal, limitada a até vinte e cinco por cento acima do preço dos produtos manufaturados e serviços estrangeiros.

Verifica-se que com a medida os produtos nacionais poderão concorrer em certames licitatórios com preços superiores em até $25 \%$ aos de concorrentes estrangeiros. Importante observar a justificativa explanada na Exposição de Motivos da MP 495/2010 quanto a esta margem de preferência, que poderá resultar em compras mais onerosas ao Poder Público:

8. ...O $\S 6^{\circ}$ do referido artigo estipula a margem de preferência, por produto, serviço, grupo de produto ou grupo de serviços em até $25 \%$ acima do preço dos produtos manufaturados e serviços estrangeiros. Trata-se, a propósito, de diretriz de política pública que se coaduna ao princípio isonômico, referenciado no caput do artigo $3^{\circ}$ da Lei $\mathrm{n}^{\circ} 8.666$, de 1993, considerando-se o intuito do poder público em assegurar, com base em critérios de proporcionalidade e razoabilidade, adequados padrões de equilíbrio concorrencial nos certames licitatórios e, desta forma, propiciar, efetivamente, condições equânimes na oferta de produtos e serviços nacionais e estrangeiros. (Destacou-se)

Verifica-se que o Poder Executivo Federal parte da premissa de constatação de uma situação de desigualdade entre concorrentes nacionais e estrangeiros, e alega com isso a intenção da medida de dar efetividade ao princípio isonômico, tornando o processo de competição em licitações mais equânime.

Por obviedade a medida não se resume à tentativa de igualar concorrentes em desvantagem em certames licitatórios, proporcionando maiores chances de competição aos desfavorecidos, pois com a medida institui-se uma política pública que visa promover a proteção e o desenvolvimento do mercado nacional, mesmo que com isso o Estado passe a realizar contratações públicas mais onerosas.

Pereira (2010) traz a opinião de Tom Buschmann, profissional atuante em licitações no Reino Unido sobre a nova medida (PEPPOL - Pan-European Public Procurement Online, em LinkedIn, acesso em 17 de agosto de 2010): 
tratégicos que precisam ser controlados/desenvolvidos/apoiados por recursos brasileiros, o que é compreensível. Estabelece ainda que para todos os demais produtos e serviços há um limite para a discriminação de empresas estrangeiras, definindo que as entidades governamentais poderão exigir de empresas estrangeiras que sejam $25 \%$ ou mais competitivas em preço que as empresas nacionais, mas não mais. E esta discriminação precisa ser amparada em estudos de mercado.

Portanto, empresas estrangeiras precisarão ser tratadas com igualdade em relação a empresas brasileiras que sob certas circunstâncias poderiam oferecer seus serviços no máximo $25 \%$ mais caros do que os de tais firmas estrangeiras. Isto é justo quando se percebe que as exportações para o Brasil em geral não exigem que o exportador recolha IVA, mas as empresas brasileiras são obrigadas a pagar ICMS (um IVA cobrado pelo Estado), com a alíquota média de $20 \%$. Na prática, empresas estrangeiras poderiam facilmente ser competitivas em preço, dependendo da sua visão acerca da taxa de câmbio do real brasileiro, seu acesso a capital estrangeiro de menor custo e a dimensão dos impostos de importação. Imagine-se uma empresa que tenha um produto suficientemente único: quando opera a partir de outro país do Mercosul, quando estabelece uma parceria com uma empresa brasileira ou mesmo quando opera de fora do Mercosul e simplesmente com preço competitivo em reais brasileiros: o que poderia ser contra receitas e margens crescentes em função das oportunidades possibilitadas pelo governo brasileiro?

O mesmo site exibe a opinião de TIM MCGRATH, para quem a nova legislação irá "penalizar empresas estrangeiras de menor porte (que não têm condições de instalar-se no Brasil) que participem de licitações. Parece mais uma barreira que um incentivo. Como tais organizações menores tendem a oferecer soluções inovadoras, esta situação também pode não vir ao encontro do interesse do Brasil".

Como mencionado acima, a solução para esta preocupação pode ser a criação de joint ventures ou parcerias entre pequenas empresas estrangeiras e empresas locais.

No entanto a eficácia de tal dispositivo ainda depende de estudos a serem promovidos pelo Poder Executivo Federal, conforme dispõe a MP 495, in verbis:

\footnotetext{
Art. $3^{\circ}(\ldots)($ lei 8.666/93)

$\ldots$

§ 7o A margem de preferência de que trata o § 6o será estabelecida com base em estudos que levem em consideração: (Incluído pela Medida Provisória n ${ }^{\circ} 495$, de 2010) I - geração de emprego e renda; (Incluído pela Medida Provisória ${ }^{\circ}$ 495, de 2010) II - efeito na arrecadação de tributos federais, estaduais e municipais; e (Incluído pela Medida Provisória $n^{\circ}$. 495, de 2010)

III - desenvolvimento e inovação tecnológica realizados no País. (Incluído pela Medida Provisória $n^{\circ}$. 495, de 2010).
}

A legitimidade do fator de discriminação criado pela MP deve se amparar em estudos que comprovem como a medida que, ressalte-se, poderá resultar em compras mais onerosas ao Poder Público, atenderá à satisfação do interesse da coletividade. 
É possível ainda ser criada a denominada "margem de preferência adicional" para os produtos remanufaturados e para os serviços nacionais resultantes de desenvolvimento e inovação tecnológica realizados no País. Por exemplo, tem-se o disposto no art. $6^{\circ}$ do Decreto 7.174/2010, que considera bens e serviços de informática e automação com tecnologia desenvolvida no País aqueles cujo efetivo desenvolvimento local seja comprovado junto ao Ministério da Ciência e Tecnologia, na forma por este regulamentada.

Dentro de parâmetros de razoabilidade, a medida cuidou de prever a restrição à aplicabilidade do critério de preferência aos produtos manufaturados e serviços nacionais, bem como à margem de preferência adicional para os produtos manufaturados e para os serviços nacionais resultantes de desenvolvimento e inovação tecnológica realizados no país, quando não houver produção suficiente de bens manufaturados ou capacidade de prestação dos serviços no País, conforme disciplina o $\S 9^{\circ}$ do art. $3^{\circ}$ incluído pela MP 495.

A MP 495 externa ainda a preocupação do Governo em respeitar o Protocolo de Contratações Públicas do Mercosul, celebrado em 20 de julho de 2006, que, uma vez ratificado, estenderá a margem de preferência aos bens e serviços originários dos Estados Partes do Mercosul, podendo ainda ser estendida, total ou parcialmente, aos bens e serviços originários de outros países, com os quais o Brasil venha assinar acordos sobre compras governamentais. ( $\$ 10$, do art. $3^{\circ}$ da Lei 8.666/93, acrescido pela MP 495/2010).

Conforme esclarece o Governo Federal em sua exposição de motivos, a medida coaduna-se ao disposto no parágrafo único do artigo $4^{\circ}$ da Constituição Federal, que preceitua a implementação de ações voltadas à integração econômica, política, social e cultural dos povos da América Latina, visando à formação de uma comunidade latino-americana de nações.

Previu, ademais, a MP 495/2010 (art. 3º $§ 11$ Lei 8.666/93) que os editais de licitação para a contratação de bens, serviços e obras poderão exigir que o contratado promova, em favor da administração pública ou daqueles por ela indicados, medidas de compensação comercial, industrial, tecnológica ou acesso a condições vantajosas de financiamento, cumulativamente ou não, na forma estabelecida pelo Poder Executivo Federal. (Incluído pela Medida Provisória nº. 495, de 2010).

Trata-se de inovação, na medida em que artigo $7^{\circ} \S 3^{\circ}$ da lei $8.666 / 93$ prevê ser vedado incluir no objeto da licitação a obtenção de recursos financeiros para sua execução, qualquer que seja a sua origem, exceto nos casos de empreendimentos executados e explorados sob o regime de concessão, nos termos da legislação específica. 
No entanto esclarece a exposição de motivos que este sistema, já adotado por diversos países, objetiva: (i) a ampliação do investimento direto estrangeiro; (ii) o aumento da competitividade e da produtividade da indústria nacional; (iii) o acesso a novas tecnologias e a ampliação do domínio do conhecimento tecnológico; (iv) a abertura de novos mercados; (v) o desenvolvimento da indústria nacional; (vi) o aumento da participação de bens e serviços nacionais no mercado externo; (vii) a promoção do equilíbrio ou superávit da balança comercial.

Com a edição da MP 495/10 criou-se, ademais, uma hipótese de licitação exclusiva nas contratações destinadas à implantação, manutenção e ao aperfeiçoamento dos sistemas de tecnologia de informação, e, comunicação, considerados estratégicos em ato do Poder Executivo Federal. A licitação nesta condição poderá ser restrita a bens e serviços, com tecnologia desenvolvida no País e produzidos de acordo com o processo produtivo básico de que trata a Lei no 10.176, de 11 de janeiro de 2001. Propõe o governo com a medida, adicionalmente a questões de soberania e segurança nacional, o auxílio na geração de empregos e fortalecimento desse importante setor da economia.

Por fim, criou a MP 495/10 hipótese de dispensa de licitação como medida de estímulo à construção de ambientes especializados e cooperativos de inovação, buscando na produção científica e tecnológica a obtenção de produtos ou processos inovadores, nas hipóteses de contratações, visando ao cumprimento do disposto nos artigos. $3^{\circ}, 4^{\circ}, 5^{\circ}$ e 20 da Lei $n^{\circ} .10 .973$, de 2 de dezembro de 2004. Sobre o assunto importante verificar o disposto na exposição de motivos:

21. As medidas consubstanciadas no inciso XXXI do artigo 24 da Lei $n^{\circ} 8.666$, de 1993, demonstram o claro intuito de potencializar as ações autorizadas pela Lei $n^{\circ}$ 10.973, de 2004, a denominada Lei de Inovação. Desta forma, a proposição reúne elementos para fortalecer setores industriais e serviços nacionais voltados à inovação e para alavancar o desenvolvimento tecnológico, por meio de empresas estimuladas e apoiadas para atingir tais objetivos. Registre-se, ademais, que o referido mecanismo de estímulo, na forma proposta, não se contrapõe às normas da Organização Mundial do Comércio - OMC. Especificamente no que tange às encomendas tecnológicas, referenciadas no artigo 20 da Lei n ${ }^{\circ} 10.973$, de 2004, é importante frisar que a possibilidade de dispensa de licitação para aquisição dos produtos contemplados sob esta modalidade, reúne condições para viabilizar o surgimento, o fortalecimento e a multiplicação de empresas inovadoras brasileiras, notadamente de empreendimentos atuantes em setores com amplo impacto na economia e que podem, com esse estímulo, promover efetiva autonomia tecnológica do País. 
De todos os dispositivos citados verifica-se o nítido intuito do Estado de intervir de forma indireta na economia, criando medidas de estímulo ao mercado nacional, valendo-se de sua condição de consumidor e agente normativo, promovendo políticas públicas por meio do instituto das licitações públicas.

\section{A FINALIDADE DO PROCEDIMENTO LICITATÓRIO E SUA LEGITIMIDADE COMO INSTRUMENTO DE INTERVENÇÃO NA ORDEM ECONÔMICA}

As margens de preferências à contratação de produtos manufaturados e serviços nacionais estabelecida nos supracitados $\S \S 5^{\circ}$ a 12 do artigo $3^{\circ}$ da lei 8.666/93, introduzidos pela MP 495 , constituem exceção à vedação disposta no art. $3^{\circ}, \S 1^{\circ}$ da mesma lei, que assim estabelece: preferências ou distinções em razão da naturalidade, da sede ou domicílio dos licitantes ou de qualquer outra circunstância impertinente ou irrelevante para o específico objeto do contrato, ressalvado o disposto nos $\S \S 5^{\circ}$ a 12 deste artigo e no art. $3^{\circ}$ da Lei no 8.248, de 23 de outubro de 1991. (Redação dada pela Medida Provisória nº. 495, de 2010).
}

Conforme mencionado no referido dispositivo, também constitui ressalva à vedação de preferências em licitações o previsto no art. $3^{\circ}$ da Lei $n^{\circ}$ 8.248, de 23 de outubro de 1991, que dispõe sobre a capacitação e competitividade do setor de informática e automação, que, juntamente com o Decreto federal $n^{\circ} 7.174 / 2010$, estabeleceu o direito de preferência à contratação de produtos nacionais, quando em condições equivalentes de prazo de entrega, suporte de serviços, qualidade, padronização, compatibilidade e especificação de desempenho e preço.

Estas não são as únicas medidas normativas que albergam critérios de favorecimento em licitações públicas, conforme se verifica na previsão da Lei Complementar n 123/2006, que criou o direito de preferência à contratação de micro empresas e empresas de pequeno porte em situação de empate ficto, possibilitando que as mesmas cubram o lance da empresa vencedora quando de médio ou grande porte (artigos. 44 e 45 da LC 123/06), entre outros benefícios.

Verifica-se que tal medida não implica na aquisição da proposta mais vantajosa para a Administração, visto que empresas de médio e grande porte supostamente têm maiores condições de fornecer bens e serviços com preços mais baixos e com maior qualidade. 
Também é exemplo de utilização do procedimento licitatório como estímulo ao mercado o disposto na Lei $\mathrm{n}^{\circ} 12.187 / 2009$, que em seu artigo $6^{\circ}$ institui como instrumentos da Política Nacional sobre Mudança do Clima:

\footnotetext{
Art. $6^{\circ}(\ldots)$

XII - as medidas existentes, ou a serem criadas, que estimulem o desenvolvimento de processos e tecnologias, que contribuam para a redução de emissões e remoções de gases de efeito estufa, bem como para a adaptação, dentre as quais o estabelecimento de critérios de preferência nas licitações e concorrências públicas, compreendidas aí as parcerias público-privadas e a autorização, permissão, outorga e concessão para exploração de serviços públicos e recursos naturais, para as propostas que propiciem maior economia de energia, água e outros recursos naturais e redução da emissão de gases de efeito estufa e de resíduos; (Destacou-se).
}

De todo o exposto se verifica que o procedimento licitatório vem sendo objeto de promoção de políticas públicas na órbita econômica, promovendo a discussão sobre quais devem ser as finalidades das compras públicas, pois algumas dessas medidas estão resultando em contratações mais onerosas ou desvantajosas para o Estado.

O posicionamento mais tradicional entende que os processos de aquisições públicas visam exclusivamente a garantir a contratação da melhor proposta para a Administração Pública, vista sob o aspecto econômico, garantindo o mínimo de qualidade necessário à satisfação das necessidades imediatas do ente promotor do certame.

Como há no mercado uma pluralidade de fornecedores em condições de serem contratados pela Administração, esta necessariamente deve observar o princípio da isonomia, possibilitando que todos os interessados disputem em igualdade de condições oferecendo suas propostas.

No entanto, conforme demonstram os exemplos normativos citados, vem sendo criados critérios de favorecimento que, com o suposto intuito de promover condições de igualdade entre os concorrentes, não vem necessariamente resultando em compras mais vantajosas para a Administração.

Verifica-se, portanto, que a vantajosidade da proposta pode ser mitigada para dar espaço ao favorecimento de determinados concorrentes que possuam menores condições de oferecer bens e serviços com o menor custo e maior qualidade.

Nos dizeres de Justen Filho (2010, p. 91), isso é o que se poderia chamar de "utilização promocional da contratação", onde:

O contrato administrativo seria instrumento de realização de políticas públicas rela- 
cionadas com a realização de valores essenciais à soberania e ao interesse da Nação brasileira. Ou seja, a contratação seria orientada não apenas à satisfação das necessidades imediatas da Administração Pública, mas também à concretização de certos objetivos mediatos e indiretos.

Em que pese eventual discordância quanto a validade desta atuação estatal, fato inconteste é que os procedimentos de compras públicas vem sendo tratados pelo Poder Executivo Federal como meio de intervir indiretamente na economia, que por meio de sua atividade legiferante, utiliza-se de sua condição de consumidor para estimular determinados setores da economia.

Neste sentido veio a MP 495/2010, que conforme pode se verificar de sua exposição de motivos, E.M.I. No 104/ MP/MF/MEC/MCT, de 18 de junho de 2010 (BRASIL, 2010), expressamente se reconhece o:

Manifesto propósito de adoção de medidas que agreguem ao perfil de demanda do setor público, diretrizes claras atinentes ao papel do Estado na promoção do desenvolvimento econômico e fortalecimento de cadeias produtivas de bens e serviços domésticos. Nesse contexto, torna-se particularmente relevante a atuação privilegiada do setor público com vistas à instituição de incentivos à pesquisa e à inovação que, reconhecidamente, consubstanciam poderoso efeito indutor ao desenvolvimento do país.

4. Com efeito, observa-se que a orientação do poder de compra do Estado para estimular a produção doméstica de bens e serviços constitui importante diretriz de política pública. São ilustrativas, nesse sentido, as diretrizes adotadas nos Estados Unidos, consubstanciadas no "Buy American Act", em vigor desde 1933, que estabeleceram preferência a produtos manufaturados no país, desde que aliados à qualidade satisfatória, provisão em quantidade suficiente e disponibilidade comercial em bases razoáveis. No período recente, merecem registro as ações contidas na denominada “American Recovery and Reinvestment Act", implementada em 2009. A China contempla norma similar, conforme disposições da Lei n ${ }^{\circ}$ 68, de 29 de junho de 2002, que estipulada orientações para a concessão de preferência a bens e serviços chineses em compras governamentais, ressalvada a hipótese de indisponibilidade no país. $\mathrm{Na}$ América Latina, cabe registrar a política adotada pela Colômbia, que instituiu, nos termos da Lei $\mathrm{n}^{\circ} 816$, de 2003 , uma margem de preferência entre $10 \%$ e $20 \%$ para bens ou serviços nacionais, com vistas a apoiar a indústria nacional por meio da contratação pública. A Argentina também outorgou por meio da Lei nº 25.551, de 28 de novembro de 2001, preferência aos provedores de bens e serviços de origem nacional, sempre que os preços forem iguais ou inferiores aos estrangeiros, acrescidos de 7\% em ofertas realizadas por micro e pequenas empresas e de 5\%, para outras empresas. 6. A modificação do caput do artigo $3^{\circ}$ visa agregar às finalidades das licitações públicas o desenvolvimento econômico nacional. Com efeito, a medida consigna em lei a relevância do poder de compra governamental como instrumento de promoção do mercado interno, considerando-se o potencial de demanda de bens e serviços domésticos do setor público, o correlato efeito multiplicador sobre o nível de atividade, a geração de emprego e renda e, por conseguinte, o desenvolvimento do país. 
9. Considera-se, nesse sentido, que a orientação da demanda do setor público preferencialmente a produtos e serviços domésticos reúne condições para que a atuação normativa e reguladora do Estado efetive-se com maior eficiência e qualidade do gasto público e, concomitantemente, possa engendrar poderoso efeito multiplicador na economia mediante: (i) aumento da demanda agregada; (ii) estímulo à atividade econômica e à geração de emprego e renda; (iii) incentivo à competição entre empresas domésticas, particularmente no que tange a setores e atividades de pesquisa e desenvolvimento tecnológico; (iv) mitigação de disparidades regionais; e (v) incentivo à geração de emprego em segmentos marginais da força de trabalho.

14. As disposições contidas no inciso III do $\S 7^{\circ}$ e no $\S 8^{\circ}$, ambos do artigo $3^{\circ}$ da Lei $\mathrm{n}^{\circ} 8.666$, de 1993, têm por objetivo fomentar o desenvolvimento de tecnologia nacional. Sabe-se que tecnologia é, cada vez mais, o fator determinante da competitividade internacional das empresas e da prosperidade das nações. A intervenção estatal, com a utilização do poder de compra fomentando a inovação tecnológica, faz-se necessária no Brasil, tendo em vista que, muito embora o País tenha avançado na produção científica e tecnológica nos últimos anos, registramos relativamente poucas patentes em comparação com os países desenvolvidos.

Não se pode ignorar a legitimidade de práticas governamentais nessa ordem em face da Constituição. Nesse sentido posiciona-se Justen Filho (2010, p. 91) para quem:

O Estado brasileiro dispõe do dever-poder de incentivar o desenvolvimento da indústria nacional, protegendo o emprego para os brasileiros e reconhecendo preferências em favor do progresso da Nação. A utilização dos recursos estatais (inclusive por meio de contratações administrativas) como instrumento de defesa do interesse nacional é um dever do governante, diretamente derivado dos princípios fundamentais: soberania nacional, República, dever de redução do desemprego e assim por diante.

Este é o posicionamento veiculado no editorial do jornal Folha de São Paulo (Apud NAVES; CAMPOS SILVA, 2010) onde esclarece que:

\begin{abstract}
A política de compras governamentais é utilizada por muitos países como instrumento de desenvolvimento econômico e incorporação de tecnologia. Como as compras públicas tendem a ter um peso grande na economia, seu direcionamento local pode contribuir para viabilizar cadeias industriais que necessitam de escala, o que é frequente em setores de tecnologia mais avançada.
\end{abstract}

Em que se pese a relevância dos objetivos e a necessidade dessas medidas, não se pode deixar de analisar a validade das discriminações propostas. É evidente que qualquer critério de favorecimento deve pautar-se pela proporcionalidade, demonstrando-se de forma devidamente motivada como a restrição à competitividade proposta resultará na promoção do bem comum. 
Deve assim a Administração justificar-se de modo a legitimar compras mais onerosas do que as que realizaria em um mercado sem sua intervenção, de forma a comprovar a relação direta entre as contratação públicas e a obtenção do bem comum almejado por sua política econômica.

É manifesta a viabilidade de intervenção do Estado no domínio econômico por meio das compras públicas, no entanto esta atuação deve ser a exceção, devendo ser avaliada a racionalidade em se onerar os processos de compras para desenvolver determinados setores da economia, em especial se a medida proposta de fato é apta a alcançar a política proposta, ou se existiriam outros meios de intervenção estatal, como políticas fiscais e tributárias, que alcançariam o mesmo fim com maior eficácia e menor onerosidade aos cofres públicos.

\section{O RESGUARDO CONSTITUCIONAL SOBRE A MATÉRIA E A LEGITIMIDADE DA MEDIDA PROVISÓRIA COMO INSTRUMENTO DE INTERVENÇÃO NO DOMÍNIO ECONÔMICO}

Conforme consta em sua exposição de motivos, o fundamento constitucional da MP 495 encontra-se nos seguintes dispositivos: (i) inciso II do artigo $3^{\circ}$, que inclui o desenvolvimento nacional como um dos objetivos fundamentais da República Federativa do Brasil; (ii) incisos I e VIII do artigo 170, atinentes às organização da ordem econômica nacional, que deve observar, entre outros princípios, a soberania nacional e a busca do pleno emprego; (iii) artigo 174, que dispõe sobre as funções a serem exercidas pelo Estado, como agente normativo e regulador da atividade econômica; e (iv) artigo 219, que trata de incentivos ao mercado interno, de forma a viabilizar o desenvolvimento cultural e sócio-econômico, o bem estar da população e a autonomia tecnológica do país.

A ordem econômica rege-se pela livre iniciativa, fundamento da República que determina que o Estado, em regra, não deve intervir na atividade econômica. No entanto, conforme dispõe o artigo 174 da Constituição Federal, é permitido ao Estado intervir na economia de forma indireta, atuando como agente normativo e regulador da atividade econômica, por meio incentivos institucionalizados em políticas públicas.

Nesta função o Estado incentivará e promoverá o desenvolvimento econômico e social para assegurar para todos uma existência digna. E assim atua, pois conforme lembra Marques Neto (2002, p. 201), a Administração Central "se incumbe da formulação e do planejamento das políticas públicas voltadas à promoção dos interesses públicos difusos, ou seja, a reduzir e equalizar as hipossuficiências sociais". 
Sobre o papel do Estado na regulação econômica, lembra Carvalho Jr. (2010, p. 129) que esta atuação estatal tem um perfil e uma complexidade que vão além das chamadas Agências Reguladoras, uma vez que o "Estado realiza regulação por meio dos mais variados mecanismos; da política de comércio exterior, passando pela política de câmbio, à política tributária, chegando às normas necessariamente técnicas".

Nesta seara, o Estado intervém na atuação dos agentes privados, deixando sua posição de mero observador, emitindo normas de conduta para controlar e fiscalizar o particular, como também para estimular determinados setores da economia.

Reconhecendo a dimensão de seu poder de compra, o Estado percebe ser capaz de intervir na economia na condição de consumidor, influenciando o mercado por meio de contratações públicas mediante critérios de preferência. Esses critérios estimulam determinados setores da economia a se desenvolverem, com vistas a reduzir desigualdades concorrenciais de fato, por exemplo, entre pequenas e grandes empresas, ou entre mercados nacionais e estrangeiros.

O Estado reconhece não haver livre concorrência entre todos os segmentos da economia, e tenta diminuir as disparidades naqueles setores considerados estratégicos ao desenvolvimento nacional, vindo a se contratar com maior freqüência com os segmentos empresariais que pretende ver fortalecido, até que estes tenham reais condições de competir no mercado sem o seu auxílio. Exemplo dessa política é preferência em licitações dada às micro empresas e empresas de pequeno porte, que quando auferem rendimentos que lhe retiram dessa condição, não mais usufruem do benefício por terem alcançado o crescimento visado pela medida.

Por meio desta atuação o Estado assume o ônus de desempenhar um papel de consumidor distinto do consumidor comum dentro da iniciativa privada - que elegerá o bem ou serviço com o menor custo e a maior qualidade disponível. O Estado passa a realizar contratações que não necessariamente sejam as mais vantajosas para o seu interesse imediato - a satisfação de sua necessidade - mas que, na sua concepção de política pública, resultará de forma mediata em um maior desenvolvimento da economia, com geração de empregos e rendas.

No caso em análise, em que o Estado atua como indutor da economia se valendo de sua condição de consumidor, não se fala em normas impositivas aos particulares, e sim em normas que vinculam exclusivamente o próprio Estado. Cria com a medida políticas públicas que não impõe condutas aos particulares, e sim cria condições para que estes possam, à sua livre escolha, se beneficiarem de condições privilegiadas para se desenvolverem.

Ocorre que o Estado não pode atuar como agente normativo de forma arbitrária, pois seus limites estão estabelecidos pela própria Constituição em seu art. 170 e pelos princípios do 
direito econômico. A legitimidade da atuação estatal nestas condições está em seu caráter excepcional, faticamente justificado e amparado no ordenamento jurídico que lhe dá suporte.

Isso porque, a própria Constituição Federal em seu artigo 37, inciso XXI impôs ao Estado a observância do princípio da isonomia, determinando que as obras, serviços, compras e alienações serão contratadas mediante processo de licitação pública que assegure igualdade de condições a todos os concorrentes, devendo o Estado atuar em conformidade com os princípios da impessoalidade e moralidade.

Com sua atuação normativa criando distinções e preferências em certames licitatórios, visualiza-se uma aparente contradição na atuação estatal, pois o agente normativo cria benefícios que desigualam as condições de participação de potenciais concorrentes em certames licitatórios - violando em tese o princípio da isonomia, para com a medida promover justamente uma maior igualdade de disputa entre esses setores no mercado a médio prazo, que, sem a intervenção do Estado, teriam menores chances de se desenvolver e competir.

Diante da imposição constitucional de observância ao princípio da isonomia, haverá a necessidade de que a criação de distinções e preferências por meio de políticas públicas, respaldadas em outros valores também albergados pela Constituição - como a proteção e incentivo ao mercado interno -, justifique a quebra de isonomia proposta, demonstrando-se os benefícios ao interesse público que a medida visa atingir.

Há assim manifestações de preocupação com a quebra de isonomia proposta pela MP 495, conforme adverte Rodrigues e Gonçalves (2010), para quem as medidas acabam por abrir espaço para a atuação de lobistas e, no limite, podem incentivar a corrupção. E prossegue:

\footnotetext{
Isso porque ficará a cargo do poder público determinar qual "margem de preferência" dada aos produtores nacionais. Ou seja, empresários terão incentivos a pressionar o governo por meio de lobbies (ou até pagamentos diretos), de modo a garantir uma maior vantagem nas compras públicas. Dito de outra forma, as medidas podem reduzir a produtividade, já que favorecem a busca de favores políticos em detrimento da inovação e eficiência.
}

Assim, diante das fragilidades das políticas econômicas propostas pelo Executivo, no âmbito das licitações, entra-se na seara de outra discussão, se seria a medida provisória instrumento legítimo para o Estado intervir na economia, uma vez que afasta o controle e a discussão mais ampla pelo Poder Legislativo das políticas públicas que se pretende efetivar.

Pela exposição de motivos da MP 495/2010, a justificativa para a urgência das medidas residiria: 


\begin{abstract}
Por um lado, pela necessidade de ações tempestivas que promovam a indústria e os prestadores de serviços brasileiros, incentivando-os a aprimorarem a qualidade de seus produtos e serviços, pela rápida deterioração da balança comercial no período recente e pela atuação agressiva adotada por alguns países que, devido ao fraco desempenho dos seus mercados internos, estão buscando espaço nos mercados internacionais. Nada obstante, também se deve ter atenção ao fato de que vários países adotam práticas semelhantes, as quais foram reforçadas em função da crise internacional, deixando produtos brasileiros em desvantagem nas compras governamentais daqueles países. A relevância da medida é dada pelo tamanho dos setores da indústria e dos serviços no Brasil que, juntos, respondem por mais de $80 \%$ do PIB e pela representatividade do consumo do governo, considerado o montante de recursos públicos alocado às compras governamentais de bens e serviços.
\end{abstract}

Sem adentrar ao mérito da relevância e urgência da medida, que ainda poderá ser declarada inconstitucional, o fato é que a discussão reveste-se de extrema importância. Conforme aponta Fonseca (2010, p. 58), é fato que a condição dinâmica do mercado, tanto no seu contexto internacional quanto nacional, não é compatível com o demorado processo legislativo de elaboração de leis ordinárias.

Para isso poderia o Poder Executivo se valer das medidas provisórias, no entanto alerta o autor que essas medidas não podem se confundir com o desregramento legiferante, e prossegue: “deve-se perguntar se as medidas provisórias têm por finalidade reger o desenvolvimento econômico, ou têm por objetivo favorecer ou pegar de surpresa os setores econômicos interessados ou envolvidos" (FONSECA, 2010, p. 59).

Considerando que a medida provisória afasta a discussão e apreciação pela sociedade das políticas públicas propostas, o correto na visão do autor é que estas, antes de serem editadas, fossem submetidas à consulta pública, ao crivo de especialistas em questões jurídicas, econômicas, ambientais entre outros, em condições de avaliar a pertinência dessas mediadas que são mais relevantes que urgentes.

Tem-se assim um conflito a ser analisado no caso concreto, onde as instituições de controle deverão verificar a compatibilidade da medida provisória para intervir na ordem econômica dada a subjetividade dos conceitos de "relevância" e "urgência" dentro de um contexto jurídico-econômico. 


\section{CONCLUSÃO}

O Estado exerce um papel indutor na economia ao criar leis, incentivos, impostos, bem como se valendo da condição de consumidor mais significativo do mercado. Por meio do seu poder de compra o Estado atua como agente normativo criando preferências nas licitações públicas de modo a incentivar determinados setores da economia considerados estratégicos ao desenvolvimento nacional.

Em especial por meio da MP 495/2010 o Estado criou medidas de proteção a determinado mercado - o de produção de bens e serviços nacionais - com a finalidade de promover o desenvolvimento da política econômica nacional, bem como estimulou o incentivo tecnológico.

A aplicabilidade das mudanças trazidas pela MP 495 ainda depende em sua grande maioria de regulamentação. Mas não se pode desconsiderar a sua importância como um reconhecimento pelo Estado da utilização de sua condição de consumidor para a promoção de políticas públicas.

O objetivo proposto pela medida encontra amparo e limites na Constituição Federal, que está autorizado a intervir de forma indireta como agente normativo e regulador da atividade econômica para promover o desenvolvimento nacional promovendo medidas como as de incentivos ao mercado interno.

Em que se pese a necessidade de uma medida normativa ágil para responder às necessidades de mudanças na economia, corre-se o risco de promoverem-se arbitrariedade e favoritismos nas licitações sem correlação com o interesse público. Cabe assim à sociedade e aos organismos de controle fiscalizarem a legitimidade da política proposta, em especial se há relação entre as contratações públicas e a satisfação do bem comum, e não o simples favorecimento de um grupo privilegiado de empresários.

\section{REFERÊNCIAS}

BRASIL. Medida Provisória n ${ }^{\circ}$ 495, de 19 de Julho de 2010. Altera as Leis nos 8.666, de 21 de junho de 1993, 8.958, de 20 de dezembro de 1994, e 10.973, de 2 de dezembro de 2004, e revoga o $\S 1$ o do art. 2o da Lei no 11.273, de 6 de fevereiro de 2006. Disponível em: $<$ http://www. planalto.gov.br/ccivil_03/_Ato2007-2010/2010/Mpv/495.htm>. Acesso em: 20 out. 2010.

BRASIL. Exposição de Motivos da Medida Provisória N 495. E.M.I. N. 104/MP/MF/MEC/ MCT. Brasília, 18 de junho de 2010. Disponível em: <http://www.planalto.gov.br/ccivil_03/ 
Ato2007-2010/2010/Exm/EMI-104-MP-MF-MEC-MCT-MPV-495-10.htm>. Acesso em: 20 out. 2010.

BRASIL.Lei $N^{0}$ 8.666, de 21 de junho de 1993. Regulamenta o art. 37, inciso XXI, da Constituição Federal, institui normas para licitações e contratos da Administração Pública e dá outras providências. Diário Oficial da União, 22 jun. 1993. Disponível em: $<$ http://www.planalto.gov. br/ccivil_03/Leis/L8666cons.htm>. Acesso em: 28 out. 2010.

CARVALHO JR., Itamar. Constituição Federal de 1988: liberdade, regulação e concorrência. In: ZANOTTA, Pedro; BRANCHER, Paulo. Desafios atuais da regulação econômica e concorrência. São Paulo: Atlas, 2010.

FONSECA, João Bosco Leopoldino da. Direito econômico. Rio de Janeiro: Forense, 2010.

JUSTEN FILHO, Marçal. Comentários à Lei de Licitações e Contratos Administrativos. 14. ed. São Paulo: Dialética, 2010.

MARQUES NETO, Floriano Peixoto de Azevedo. Regulação estatal e interesses públicos. São Paulo: Malheiros Editores, 2002.

NAVES, Rubens; CAMPOS DA SILVA, Guilherme Amorim. O dilema democrático das medidas provisórias. Disponível em: http://www.migalhas.com.br/depeso/16,MI117172,31047$\mathrm{O}+$ dilema+democratico +das+medidas+provisorias . Acesso em: 20 out. 2010.

PEREIRA, César A. Guimarães. AMPn ${ }^{\circ} .495$ e as alterações na legislação sobre licitações. 2010. Disponível em: $<$ http://www.justen.com.br//informativo.php?informativo $=42 \&$ artigo $=458>$. Acesso em: 25 ago. 2010.

RODRIGUES, Mauro; GONÇALVES, Carlos Eduardo. Coluna: Sob a lupa do economista. Revista época. Disponível em: <http://colunas.epoca.globo.com /sobalupadoeconomista/ $>$. Acesso em: 20 out. 2010.

TORRES, Ronny Charles Lopes de. Leis de Licitações Públicas Comentadas. 3. ed. Ed. Juspodivum, 2010. Disponível em: < http://www.editorajuspodivm.com.br/i/f /Nota $\%$ 20de $\% 20$ atualiza $\% \mathrm{C} 3 \% \mathrm{~A} 7 \% \mathrm{C} 3 \% \mathrm{~A} 3 \mathrm{o} \% 20 \mathrm{em} \% 20$ fun $\% \mathrm{C} 3 \% \mathrm{~A} 7 \% \mathrm{C} 3 \% \mathrm{~A} 3 \mathrm{o} \% 20 \mathrm{da} \% 20 \mathrm{MP} \% 20$ 495.2010.pdf>. Acesso em: 20 out. 2010. 